\title{
Seeking everyday wellbeing: the coast as a therapeutic landscape
}

\begin{abstract}
Recent research suggests coastal environments may promote human health and wellbeing. This article explores the diverse coastal experiences sought out by residents of two towns in south west England to promote and preserve their personal wellbeing in the context of their everyday lives. It draws on the findings of an in-depth interpretive study conducted from May to November 2013 that examined the relative contribution of varied green and blue space experiences to individual wellbeing through the life course. Personalised activity maps produced using accelerometer and Global Positioning System (GPS) data were used to guide in-depth geo-narrative interviews with a purposive sample of 33 participants. This was combined with a subset of nine case study go-along interviews in places deemed therapeutic by the participants themselves, offering deeper insight into the lived experiences and relationships playing out within such places. Situated in a novel adaptation of the therapeutic landscapes framework, this article explores how symbolic, achievement-oriented, immersive and social experiences contributed to participants' sense of wellbeing in their local coastal areas. Participants expressed particularly strong and often enduring connections to the local coastline, with different coastal stretches perceived to cater for varied therapeutic needs and interests, at multiple scales and intensities. The findings suggest the need for greater acknowledgement of people's emotional, deeply embodied and often shared connections to the coast within coastal management policy and practice, both nationally and internationally. Importantly, such efforts should recognise the fluid, dynamic nature of this land-sea boundary, and the valued therapeutic experiences linked to this fluidity.
\end{abstract}

Keywords: South-west England; Blue space; Therapeutic landscapes; Wellbeing; Geo-narratives

\section{Introduction}

Post-review pre-print. Published as:

Bell, SL., Phoenix, C., Lovell, R. and Wheeler, BW. (2015) Seeking everyday wellbeing: The coast as a therapeutic landscape. Social Science \& Medicine, 142: 56-67. 
The health promotion (or 'salutogenic') potential of natural environments is now widely acknowledged and researched (Hartig et al., 2014). Much of this research has focused on the health and wellbeing benefits of 'green' space proximity or exposure - woodlands, parks, gardens etc - (de Vries et al., 2003; Maas et al., 2006), with less attention given to the specific benefits of 'blue' spaces. Blue spaces are environments defined by the presence of water and include inland and coastal aquatic environments (White et al., 2010; Völker and Kistemann, 2011; 2013). Positive associations between coastal proximity and indicators of general health, mental health and physical activity have been identified (Bauman et al., 1998; Witten et al., 2008), even after controlling for the level of green space in the living environment (Wheeler et al., 2012; White et al., 2013a; 2014). In this paper, we explore the diverse therapeutic experiences sought out at the coast, drawing on the findings of an in-depth, interpretive, mixed methods study conducted with residents of two coastal towns in south west England. Grounded within the empirical data, we situate the experiences in relation to theoretical constructs (including therapeutic landscapes, flow, attention restoration, peak diminutive experiences) that seek to explain the sense of wellbeing gained by people through their coastal interactions.

\subsection{Historical 'healing' at the coast}

There have been various shifts in cultural interpretation of the coast over time, from its enjoyment amongst the Ancient Greeks and Romans as a place of pleasure and beauty, to its avoidance throughout the Middle Ages as 'wild and untamed' (Tuan, 1974), and its gradual integration into societal activities from the 1700 s onwards. This reintegration saw the coast reframed as: a livelihood source and integral part of working life, in the 1700s (Lenček and Bosker, 1998); a space for emotional release and spiritual renewal, driven by notions of the Sublime and the Romantic literary movement of the 1800s; a space for medicinal cold-water bathing, perceived as a hygienic alternative to inland public bathing houses from the 1700 s -1800 s; a setting for open air recreation and pleasure in the late 1800 s to mid 1900s (Walton, 2000); and a peaceful site for retirement in the 1960s, leading to 
what Andrews and Kearns (2005) describe as 'Costa Geriatrica'. Despite a significant drop in domestic seaside holidays following the rise in affordable air travel and package tours abroad in the 1960 s and 70 s, the continued role of the coast as a contemporary leisure space, valued by local residents for both individual and family wellbeing, is apparent within a number of recent studies (Ashbullby et al., 2013; White et al., 2013b). Cultural geographers, in particular (e.g. Game and Metcalfe, 2011; Kearns and Collins, 2013) have commented on the potential of the coast to "generate a palpable intensity of feeling" (Ryan, 2012: 3). In this paper, we draw on this work and new empirical data to explore how and why the coast is able to generate such intensity of feeling, specifically in the context of human wellbeing.

\subsection{What do we mean by 'wellbeing'?}

This paper supports recent calls for a dynamic conception of health, emphasising the "capacity to maintain and restore one's integrity, equilibrium and sense of wellbeing" (Huber et al., 2011, p. 12) through life. The concept of 'being well', and how best to measure wellbeing, has been the subject of much debate throughout recent history. As highlighted by Reid and Hunter (2011), personal wellbeing is rarely the same for all individuals, and people's conceptions of wellbeing may change over time. This creates challenges for research since standardised measures of health and wellbeing may not resonate with the wellbeing priorities of individuals under study. With this in mind, we follow the example of Dinnie et al. (2013, p. 104), who advocate exploring people's personal sense of wellbeing through asking "about their experiences, feelings and interactions with the world and their perceptions of those experiences". Such in-depth narrative accounts provide nuanced insights into people's own wellbeing priorities and the personal salience of different settings (including the coast) in meeting these priorities. This approach is consistent with the recognition in the therapeutic landscapes literature that place-based wellbeing encounters are best approached as "a relational outcome, as

Post-review pre-print. Published as:

Bell, SL., Phoenix, C., Lovell, R. and Wheeler, BW. (2015) Seeking everyday wellbeing: The coast as a therapeutic landscape. Social Science \& Medicine, 142: 56-67. 
something that emerges through a complex set of transactions between a person and their broader socio-environmental setting" (Conradson, 2005, p. 338).

\subsection{The concept of 'therapeutic landscapes'}

Historically, specific blue spaces have gained long-standing reputations for healing, including 'sacred' springs, holy wells, and coastal areas (Fox and Lloyd, 1938; Gesler, 1996; 2003; Foley, 2011). These have been described in previous studies as 'therapeutic landscapes'; landscapes where "the physical and built environments, social conditions and human perceptions combine to produce an atmosphere which is conducive to healing" (Gesler, 1996, p. 96). This definition conveys the importance of understanding the physical and social wellbeing potentials of a given space, but also the more subjective ways in which people engage in, experience and interpret that space (Braubach, 2007).

Much of the early therapeutic landscapes research focused on the wellbeing properties of widely acknowledged, 'extraordinary' places of healing, such as pilgrimage sites and spas (Gesler, 1992; 1996). Water featured in many of these places, often due to long-standing spiritual beliefs that spring water drawn from specific 'sacred' sites possessed healing powers (Williams, 2010; Foley, 2011). In the $17^{\text {th }}$ Century, physicians began to analyse the chemical properties of these 'healing' waters in the hope of improving their use in medical treatments. Centuries of these experiments, however, found little evidence of any 'healing' properties. As such, these physicians catalysed the demise of many 'therapeutic' baths and spas (Gesler, 2003). Yet, in focusing solely on reductionist testing of the waters, these physicians had largely failed to appreciate the significance of the suite of embodied spiritual and social rituals performed at these sites. Several researchers have since returned to sites with reputational healing properties to understand these wider 'therapeutic assemblages' (Foley, 2011; Gesler, 1996; 2003; Williams, 2010).

Recognising the 'exclusivity' and increasing commodification of these 'extraordinary' places of healing - and the infrequency with which they are experienced through the life course (Willis, 2009) - 
researchers have also turned their attention to the therapeutic potential of places encountered routinely within everyday life. This is based on the perception that frequently accessed spaces - such as community gardens, woodlands, urban riverside spaces, beaches etc - may be more important for longer-term health promotion (Milligan et al., 2005; Milligan and Bingley, 2007; Cattell et al., 2008; Völker and Kistemann, 2013). This latter interpretation of therapeutic landscapes, as sites of health promotion (rather than solely healing), is adopted within this paper.

Notably, the places discussed in the therapeutic landscapes literature to date range from those with perceived aesthetic value (including green and blue spaces) to those whose therapeutic qualities may be imperceptible to an outsider, including a sense of security and inclusion nurtured through the development of supportive social networks over time (Smyth, 2005; Wakefield and McMullan, 2005). Valuable insights can be drawn here from the diverse body of literature on 'sense of place', increasingly considered central to positive wellbeing experiences in much of the therapeutic landscapes literature (Eyles and Williams, 2008). Kyle et al. (2004) discuss 'sense of place' as a broad construct, comprising four dimensions:

- Place attachment: the affective component, describing emotional attachments to a setting.

- Place identity: the cognitive component, including the values, attitudes and beliefs held by an individual in relation to settings that provide opportunities for individuals to both express and affirm their identity (that is, their sense of who they are and what defines them).

- Place dependence: the behavioural component, referring to a functional reliance on a setting to facilitate the achievement of goals and carry out desired activities.

- Social bonding: a social component, suggesting that settings can become meaningful through supporting significant social relationships and shared experiences over time.

As such, the idea that places are intrinsically therapeutic in some way has been increasingly contested in the literature (Williams, 2007). Instead, settings are likely to be experienced in different ways by 
different people, with users gaining a sense of wellbeing through appreciating various (personally relevant) phenomena within the setting (Cattell et al., 2008). For example, whilst some people perceived beaches as therapeutic spaces in which to relax, reflect, socialise or exercise, others were deterred from doing so by concerns about the health risks of sun exposure (Collins and Kearns, 2007). Similarly, drawing on the findings of a qualitative study with 16 young people in the North West of England, Milligan and Bingley (2007) argued that woodland encounters experienced as therapeutic by some were 'anxiety-inducing' for others. Variations in perceptions were not linked to age or gender, but to: differing levels of exposure to woodland environments as children; the limits imposed on play spaces by parental anxieties; and the role of myth and media sensationalism creating concerns about what may 'lurk' in forest settings.

Whilst the concept of therapeutic landscapes has evolved significantly over the last 20 years or so, a number of questions remain. For example, if places themselves are not intrinsically therapeutic, what can we learn about the diverse therapeutic landscape experiences sought out by people in the context of their everyday lives? How do shifting relationships and life circumstances influence the relative importance of these experiences, and the places in which they are sought out, over time? These gaps in our understanding inform the research questions designed for the current study: (a) What characterises participants' green and blue space therapeutic experiences? (b) What is the relative importance of different green and blue spaces for wellbeing amongst participants and why? (c) How do current life circumstances and prior place experiences shape the perceived importance of green and blue space as a therapeutic resource or otherwise? This paper focuses explicitly on the findings emerging in relation to the first research question, specifically in the context of coastal settings, which have received considerably less research attention than everyday green spaces (e.g. parks, woodlands, gardens) to date. 


\section{Methods}

As indicated above, the findings presented in this paper are drawn from a wider study seeking to explore the relative contribution of different types of green and blue spaces to individual wellbeing, examining how these contributions may be shaped by everyday routines, life circumstances and past experiences. In this paper, we focus only on the most widely discussed experiences; those sought out in coastal environments. The study was conducted from May to November 2013 in two towns in Cornwall, south west England; a county with over $720 \mathrm{~km}$ of coastline.

An interpretive, mixed method approach was designed for the study; full details of the data collection and analytical methodology have been described elsewhere (Bell et al., 2015), and are summarised here. A purposive sample of 33 participants were recruited following the delivery of study information sheets and recruitment screening questionnaires to all households within four neighbourhoods, each with comparable green space coverage, located in the two coastal towns. Two socio-economically distinct areas per town were selected, the boundaries of which were defined according to Lower Layer Super Output Areas (LSOA - an administrative unit used in England and Wales). In order to gain insights into the perceived value of green and blue spaces for wellbeing across a diversity of everyday experiences, the full study sample (characterised in the appended Supplementary Material) captured variation in green, blue and built space engagement, gender, and life circumstances. The sample included individuals aged between 25 and 85 years old; in full/part-time employment or retired; with or without children; and spanning households earning less than $f 20,000 /$ year to over $f 70,000$.

Informed consent was sought from all participants, and ethical approval for the study was granted by the University of Exeter Medical School Research Ethics Committee (Approval Reference: $\operatorname{Jan} 13 / \mathrm{B} / 002)$.

Participants carried a GeneActiv accelerometer (measuring physical activity) and QStarz BT-Q1000XT Global Positioning System (GPS, measuring location) receiver for one week. The resulting data were 
used to produce a set of personalised geo-narrative (Kwan and Ding, 2008) base-maps showing where participants went during the week, how long they stayed in different places and how active they were. Each participant's maps were then used as visual prompts to guide an in-depth interview exploring how and why they engage with different local environments to promote and maintain a sense of wellbeing. Open questioning techniques were used to explore the place narratives offered by participants in more detail, focusing on the physical and social contexts of their place interactions, associated meanings and feelings, changes over time, and any other important places not depicted on their maps. This was followed by a series of nine case-study go-along interviews with a subset of participants, in places they deemed therapeutic, offering further insights into the lived experiences and relationships playing out within such places. The benefits of this combined approach for understanding the complexities of spatial experience are discussed in detail elsewhere (Bell et al., 2015).

Multiple phases of analysis were undertaken on the data collected (with details provided by Bell et al., 2015). Following the co-analysis of the geo-narrative maps with participants, the resulting interview transcripts were subject to in-depth thematic analysis with the assistance of Nvivo 10 (qualitative analysis software). This explored how the diverse green and blue space experiences recounted by participants reflected: (a) existing cultural place narratives; (b) specific personal identities, relationships, priorities and emotions; (c) shifts through the life-course; and (d) the interview context itself (recognising how the researcher-participant interaction shaped the course of the interview). Similarities and variations (including outliers) in the wellbeing experiences emerging across participants' accounts were explored in relation to different green and blue space interactions, life circumstances and transitions, and personal identities. Although an inductive analytical approach was adopted, efforts were made to move back and forth iteratively between the data and the literature in order to examine participants' narratives in relation to existing theoretical constructs in the fields of green space, health, wellbeing, and leisure research. Critical friends (colleagues/peers who 'broaden 
the scope of perception' - Norris, 1997) were consulted throughout in order to identify personal interpretive 'blind spots', and a field diary was kept for purposes of reflexivity and transparency (Tracy, 2010).

At no point during the study were green or blue spaces indicated by the study materials or the researcher to be the primary research focus. The study was framed in a way that asked participants to consider how they interact with their local environment for health and/or happiness. In this way, the study sought to reduce the risk of recruiting only those individuals who self-identify with, or use, green and blue spaces. However, the potential environmental connotations of the term 'local environment' are acknowledged.

\section{Results and discussion}

Four (often overlapping) therapeutic experience dimensions were identified within participants' green and blue space narratives - symbolic, achieving, immersive and social. Illustrative narratives are examined in this section alongside key theoretical constructs drawn from the literature in order to understand and explain the diverse ways in which participants' coastal interactions were experienced as therapeutic.

\subsection{Symbolic therapeutic experiences at the coast}

As noted by Gesler $(1992,2003)$, places can develop 'reputations' for health and wellbeing, often through the emergence and reproduction of cultural narratives regarding the healing potential of specific environmental features. These narratives may attune individuals to certain aspects of place experience over others (Tuan, 1977), influencing the moods and emotions described by individuals in relation to different place encounters. For example, reflecting longstanding perceptions of water as 'cleansing' or 'purifying' (Völker and Kistemann, 2011), participants in the current study indicated 
feeling calmer by the sea, referring to the cleansing nature of the waves in the context of their emotions:

Amy: "If I'm kind of upset about anything or if I just need to get away for a bit, I find that being by water and just staring at the waves crashing in kind of washes your emotions away... you can get lost in that".

Other participants appreciated the 'simplicity' of the sea, illustrating Romantic notions of retreat and renewal at the coast. This is apparent in the interview extract below, in which Dean explains that his feelings about the coast have in part been shaped by a cultural reference to the ocean as 'the truth':

Dean: "I remember - when I was a teenager - watching a Bob Marley thing on TV, and he stood on a cliff and he was just pointing out into the ocean and he said, 'that there is the truth', and that kind of thing sticks with me... it's very easy to become overwhelmed or lost or over-occupied with all the details and the minutiae of life that goes on. You have to sort of press the pause button, unplug it, just stop for a minute every once in a while, on a fairly regular basis, to remind yourself that actually, that's not what it's about... I think then that the beach serves as a reminder of your sense of humanity and that you really shouldn't forget to invest in who you are ... the beach isn't everything you have to attend to. It's all the busyness and the noise that isn't there, and the fact that it is what it is, and there's no advertising trying to sell you that."

The potential for coastal interactions to promote such feelings of renewal and restoration are discussed further below in the context of immersive therapeutic experiences.

In addition to the cultural symbolism attributed to the coast, participants' narratives indicated strong personal symbolism linked to the sea. Consistent with the findings of studies conducted with coastal 
residents in New Zealand and Australia (Game and Metcalfe, 2011; Collins and Kearns, 2013), participants conveyed conscious emotional connections (described by one participant, Bill, as "an emotional response, a natural affinity") and more subconscious feelings of being 'at home' in coastal locations. Participants who had moved to Cornwall from elsewhere highlighted the novelty of living within such close proximity to the sea, describing it variously as "priceless", "magical", "fantastic", "stunning", and "our back garden beach". Reflecting a form of place identity (Kyle et al., 2004), longerterm residents felt that having the option to go to the seaside, with scenic coastlines to the north, west and south of home, distinguished Cornwall from elsewhere in the UK, giving it a unique "coasty feel":

Researcher: Where would you miss most if you were to move away from this area?

Danny: "...wherever you go, most places have got like river walks and they've got nice garden areas and stuff but being so close to the sea, I quite like that. I mean I work literally right next to the sea, I can chuck a stone and it would land in the sea so I see it all the time, and we take it for granted... you've got people that live in like Birmingham and they don't ever see the coast... like, shops, restaurants, leisure facilities are everywhere now - obviously if you go to some cities you get a lot more choice but - yeah, it'd be the actual coast, coasty feel, that's probably what l'd miss the most".

Whilst participants might not actively engage with the sea on a routine basis (as Danny notes, sometimes taking it for granted), they valued its presence, even if just viewing it through a car window or at work. This presence contributed to feelings of belonging to the locality, reflecting Tuan's (1980, p. 4) notion of 'rootedness'; a feeling of "being completely at home - that is, unreflectively secure and comfortable in a particular location". In the extract below, Maggie refers to a sea-diving accident that she was involved in three years ago to emphasise the strength of this connection; even though that 
particular coastal interaction had significant and lasting negative repercussions for her physical wellbeing, she still feels most 'rooted' when living in close proximity to the sea:

Maggie: "I don't like being far from the sea, and it's odd because I don't spend a lot of time in it... I'm not actively in the water or anything. I have done several things in the past, one which led me to be like this ((points to wheelchair)), so the sea really isn't my friend. However ((sighs)) I love it, I love having the smell of it. When I'm away from it I get really itchy and I think 'Ohh I just wanna come home'".

These emotional attachments to the coast appeared to develop through the accumulation of diverse individual and/or shared coastal experiences. Whilst some participants prioritised opportunities to use the coast to progress towards personal goals ('achieving' experiences), others valued opportunities to lose themselves ('immersive' experiences) or connect with others ('social' experiences). These are discussed in the remainder of this paper.

\section{2 'Achieving' therapeutic experiences at the coast}

Several participants referred to local coastal spaces when discussing their desire for challenge and achievement, appreciating them as both functional and pleasurable environments in which to pursue long-term personally meaningful goals and more immediate feelings of short-term cathartic release. For example, a number of participants incorporated beaches, coastal paths and sea views within selfdevised (often circular) local activity routes, usually whilst cycling, running or walking. The diverse activity opportunities provided by the coast enabled participants to tailor their routes according to energy levels, mood and time available. In this way, they could build stamina, strength and skills over time, often with the added support (and enjoyment) of friends or fellow activity club members (e.g. kayaking, surfing, cycling, running clubs). 
Consistent with existing literature on exercise in green spaces (Krenichyn, 2006), participants tended to refer to the coast as more than just an activity space. For example, one participant, Helen, compared running indoors with her outdoor coastal routes, describing activity in a gym as "just a way of doing exercise. It's not a way of making yourself content, which is really what it's about in my world". As such, running along the coastal path served purposes beyond physicality, including both cognitive and emotional release. This reflects Ryan's (2012, p. 209) suggestion that “moving physically through a place is often paralleled by emotional transitions". As discussed below, the dynamic immersive nature of coastal encounters seemed to enhance the intensity of these transitions.

Participants also valued more direct interactions with the water, highlighting how such experiences provided opportunities to master their hobbies (e.g. sea fishing, surfing, sailing, kayaking) within challenging, often unpredictable ambient conditions. This is illustrated in the extract below in which Owen describes the challenge and adrenaline release experienced when surfing in difficult weather conditions:

Owen: "...you've got like loads of white water to get out with and you've gotta duck-dive your board out with freezing cold water smashing you in the face. If you make a mistake, you could seriously injure yourself, you've gotta be on the ball. It's not relaxing but still it's brilliant!... It's like, imagine being on a roller coaster that's 100 times better than any roller coaster you'd go on... and it's not like you're just holding on, you're controlling the roller coaster and if you make a mistake, you fall off the roller coaster. Okay, you fall into water, but you still fall off, and then you end your experience, and it's just brilliant, there's nothing better! I mean I can close my eyes and re-live my biggest waves that I ever caught, every day, easily, I can easily do it, and it's absolutely photographic. What I mean is, when you get a really good wave, it is embossed in your mind forever!" 
This is an example of 'sharpened awareness' or 'peak flow' occurring during physical activity (Humberstone, 2013, p. 568), which is a subset of a wider category of 'peak experience', characterised by "moments of highest happiness and fulfilment" (Privette, 1983, p. 1362). This concept of peak experience explains why even momentary blue space experiences can leave a lasting imprint in the memory, such as that described by Owen above. These experiences are characterised by "such intensity of perception, depth of feeling, or sense of profound significance as to cause it to stand out, in the subject's mind, in more or less permanent contrast to the experiences that surround it in time and space" (Leach, 1963, p. 11).

Peak flow is a particularly intense form of another type of experience, termed 'flow' (Csikszentmihalyi, 2002). Moments of flow have been linked to enjoyable, absorbing, intrinsically rewarding and motivating activities, occurring only "when the participant's perceived level of skill is suitably matched to the perceived challenges demanded from the activity" (Pomfret and Bramwell, 2014, p. 8), contributing to a deeply satisfying experience. In successfully tackling new challenges, the challengeskill balance of an individual may escalate and deeper, 'peak' flow experiences may result. This balance is highly individualised and subjective (Beedie, 2014), varying amongst different people. As such, an activity or activity setting that facilitates experiences of peak flow for one person (e.g. Owen) may trigger anxiety or boredom in another. This was particularly apparent in participants' accounts of sailing. As illustrated in the extracts below, for example, whilst some participants (e.g. Mack) enjoyed the challenges posed by difficult weather conditions, others (e.g. Yvette) indicated a preference for calmer conditions better matched to their perceived sailing capabilities:

Mack: "It gets your mind off everything, you've gotta pay attention when you're sailing... and she ((Mack's sailing partner)) used to quite like going out in pretty rough weather and I loved it!" 
Yvette: "I don't always know that [sailing] is going to be enjoyable because sometimes the weather proves a challenge. It can be that it's actually too calm, there's no wind at all, and that's really quite hard work or it can be that it's very windy and it's a bit scary... but in certain conditions I'd say that the sailing was great... a complete away from it all sensation".

The 'achieving' experiences discussed in this section suggest that, for some participants, being active in coastal environments was able to promote the widely recognised 'eudaimonic' conception of wellbeing. This is one of two broad perspectives on mental wellbeing that are commonly acknowledged in the literature (Ryan and Deci, 2001). Whilst the alternative 'hedonic' perspective tends to equate wellbeing purely with the experience of pleasure, the 'eudaimonic' perspective recognises that not all pleasurable desires will bring long-term wellbeing if achieved, and events that do not bring immediate pleasure may nonetheless allow individuals to achieve personally meaningful goals (Reid and Hunter, 2011). Whilst the experiences discussed in this section were at times physically painful (due in part to the challenging, dynamic coastal terrain and ambient conditions), they contributed to feelings of competence, purpose and achievement amongst participants. These are important components of eudaimonic wellbeing and have been largely overlooked within the therapeutic landscapes literature to date.

\subsection{Immersive therapeutic experiences at the coast}

Several participants prioritised opportunities to 'switch off from the day-to-day', 'lose themselves' and/or gain a sense of perspective through their therapeutic experiences, many of which were sought out at the coast. These experiences tended to reflect elements of three immersive processes: (a) moments of 'flow' (Csikszentmihalyi, 2002); (b) phased processes of 'attention restoration' (Kaplan, 1995); and (c) 'peak diminutive' experiences (Pomfret, 2012), experienced as both immersive and inspiring. These processes are defined and illustrated in this section. 
In addition to the 'peak flow' experiences discussed above, it has been suggested that people can experience moments of less intense 'microflow' when absorbed in intrinsically enjoyable, personally meaningful activities. For example, when Bill was asked why he enjoys sea fishing in the summer, he explained:

Bill: "the fishing is hanging, it has nothing whatsoever to do with the fish. It's a bit like what I suppose knitting and sewing is for people - it's the thing that you use to focus your mind to silence".

Although these microflow activities (and activity settings) may be less challenging than those facilitating peak flow, they still involve a degree of focus and are experienced as pleasurably immersive (Privette, 1983; Phoenix and Orr, 2014). As such, moments of microflow may be more widely achievable in everyday life. Participants' experiences of microflow were often, however, fleeting and interspersed with different sensations through the course of the activity, such as restoration, contemplation and conversation.

Several participants valued experiences of immersive restoration at the coast, with their narratives reflecting processes described by Kaplan's (1995) theory of 'attention restoration'. This theory has been widely studied in the context of green space exposure but only recently in relation to blue space (White et al., 2010). It highlights two areas of attention in our lives. The first, 'directed attention', allows sustained focus on uninteresting subjects judged to be important; tiredness (or 'directed attention fatigue') ensues as effort is required to block out interesting but less important subjects. In contrast, the second, 'indirect attention' occurs in response to subjects that capture attention with little or no cognitive effort, allowing the brain's cognitive resources to be restored, thereby enabling a return to direct attention.

Reflecting these processes of attention restoration, participants' narratives indicated that by allowing themselves to engage with the captivating multisensory elements of the coastal setting, they were 
able to clear their mind of everyday cognitive 'noise', creating the mental space needed for deeper processes of reflection (Herzog et al., 1997). The material fluidity and sense of ongoing motion at the coast (Ryan, 2012), coupled with the expanse of the oceanic horizon, were frequently highlighted by participants in this regard. For example, in the summary of Mia's go-along interview at her local beach (presented in Figure 1), Mia notes that 'everyday it's different'. The changes occurring within coastal surroundings at varying temporal scales (geological, seasonal, daily, hourly) captured participants' attention and interest, with many describing the shifting tides, ambient weather conditions, and the appeal of encountering something different during each visit. The repetitive motion of the waves, in particular, seemed to inspire participants:

Helen: "It's forever moving, it's restless, it's beautiful... I go to certain beaches where there aren't many people and I can sit there and just watch the sea for ages...sometimes I'm with my daughter ... and we'll sit there and occasionally we'll pass a word but it's mostly just watching the waves break. It's the movement, the unsolicited movement - it happens by itself without anybody doing anything to it, absolutely natural. It's a bit like flame watching, it's beautiful, there are things happening and it relaxes you and de-stresses you". 
Figure 1. A summary of Mia's go-along interview along her local beach (October 2013, progresses in anti-clockwise direction, approx 1.5hrs duration)

\begin{tabular}{|c|c|}
\hline $\begin{array}{l}\text { 1. We left the car park, } \\
\text { picked up some dog mess } \\
\text { bags, and wandered } \\
\text { towards some steps leading } \\
\text { down to the beach. Mia } \\
\text { pointed further along: "you } \\
\text { can go down that road but I } \\
\text { like to start at one end of the } \\
\text { beach and then work my } \\
\text { way down to the other... I } \\
\text { don't come up the steps. }\end{array}$ & $\begin{array}{l}\text { 0. Walking further along, Mia noted: "The other day I walked along the Roseland coast but because } \\
\text { 'e tide was out like miles I walked on the water's edge - not the water's edge - but ((sighs)) at the } \\
\text { ottom of the cliff along all the rocks, and the tide was coming in but it was like nice and calm and I } \\
\text { ooked at it and I thought "Oh that'll take me an hour or half an hour maybe". It took me longer, } \\
\text { bviously, it always does, but... ((sudden diversion as participant's dog runs after a newly landed } \\
\text { olf ball in the neighbouring golf course))... But yeah, somewhere along the line in my life ((pause)) I } \\
\text { emember reading the book called 'Feel the fear and do it anyway'. And someone said to me, on } \\
\text { ome training I did, that they reckon that every day, you should do something that scares you. So } \\
\text { hat's what I did, but ((pause)) I was thinking, "This is really stupid, I haven't got a phone. If I do get } \\
\text { tranded, what the hell am I gonna do? I can't alert anybody, I've got no coat, you know, I've got no } \\
\text { od" ((laughs)). But, you know, none of that happened but, as I was walking, I was getting more } \\
\text { cared and more scared and more scared, and it turned out fine, you know ((sighs))". }\end{array}$ \\
\hline
\end{tabular}

1. We left the car park,

towards some steps leadin

down to the beach. Mia

pointed further along: "you

can go down that road but

that's just too much! There's

82 in total, apparently".

2. As we were walking down, a couple asked for directions to the beach. Mia responded: "when you come to the bottom here, you turn right and it will take you to the beach. Then you can walk all the way along and you don't have to look at this building site here ((laughs))... if you don't

look behind you and look straight ahead, it's beautifu!!" When they asked what the building site used to be, Mia briefly explained the history of the Cornwall Coliseum music venue before it was left derelict.

3. As we reached the beach, Mia let the dogs off their leads and stopped to look out to the sea: "It is beautiful. Everyday it's different" She pointed to a pool of light in the distance. "I like looking at things like that, where the sun comes do un comes down on the water".
.

$\downarrow$

4. Staring back at the ruin of the coliseum Mia commented: "you can imagine what it will be like, I ean there's diagrams of what there'll be a promenadel going to be a building loadsa people here after that and there's nobody... that's the beauty of it!" suppose... I'm not looking forward
9. Looking over at the Coliseum ruin, Mia explained: "they say it's a manmade beach, I don't know what bit of it is manmade... apparently they brought loads of sand in .... so where those nasty dirty brown defence things are, all along there, there's like tarmac

underneath that sand. Maybe that's to do with what was there before... and that river there is um, l've got an old book of St Austell and the river's more down towards those buildings in that so they must have retowards those buildings in that so they must have re-
channelled it but, since l've been here, that little river channelled it but, since l've been here, that little river
there never came up as far as here... it's really weird how it's changed".

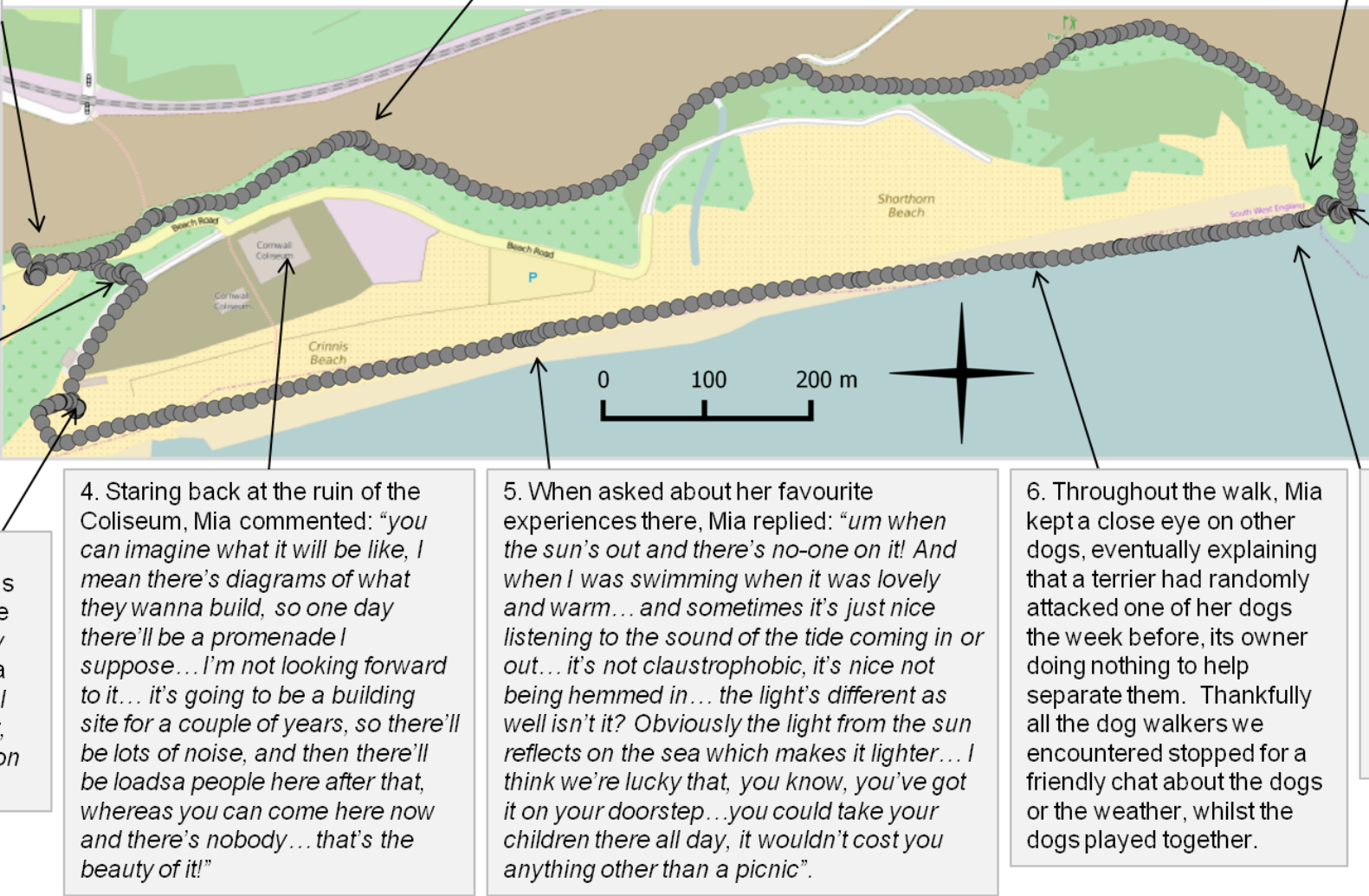

8. We paused at the end, before scrambling up the hill to reach the coastal path. Mia helped her dogs up and took a breather half-way, looking back across the bay: "you can see the water, it's so clear isn't it, there's just nothing in it.. that's another plus about this beach - I don't like, when you go swimming, touching things! It's nice just to feel the sand on your feet ((long pause))... it is peaceful isn't it, when you listen to that, that's what I like, it's just anything other than a picnic".

Post-review pre-print. Published as:

Bell, SL., Phoenix, C., Lovell, R. and Wheeler, BW. (2015) Seeking everyday wellbeing: The coast as a therapeutic landscape. Social Science \& Medicine, 142: 56-67. 
As noted by Ryan (2012) in relation to the Irish coast, the sense of relaxation invoked by this mesmerising rhythm and repetition can be punctuated by moments of intensity, contributing to a heightened awareness of spatial experience. For example, reflecting Mia's observations about the particular quality of light at the coast (Figure 1, Boxes 3, 5, 7), Ryan (2012, p. 236) discusses the 'reflective interchange' between the expanses of sea and sky. She explains that light 'animates' and 'adds a depth of intensity' to people's coastal encounters, and suggests that the sea's absorption of continually altering colours creates a sensation that 'wraps' or absorbs the individual (2012, p. 16). The appeal of 'warm' coastal colours was widely discussed by participants, with references made to the 'golden sands' of the north coast beaches, the 'blues' of the sea on sunny days, and the vegetated backdrop where the land meets the sea. One participant, Linda, compared the turquoise colour of the water in parts of Cornwall with the "grey sludge" she recalled seeing at the coast when she moved elsewhere in England for a year.

The powerful sense of sound also seemed to contribute to the intensity of participants' restorative experiences at the coast, with many commenting on the duality of the sea's 'moods'. As illustrated in Figure 2 - an extract from Rich and Angie's shared go-along interview at their local beach - the soothing effect of the waves gently breaking on a calm day was contrasted with the invigoration of the sea's power on a stormy day. 
Figure 2. The 'moods' of the sea
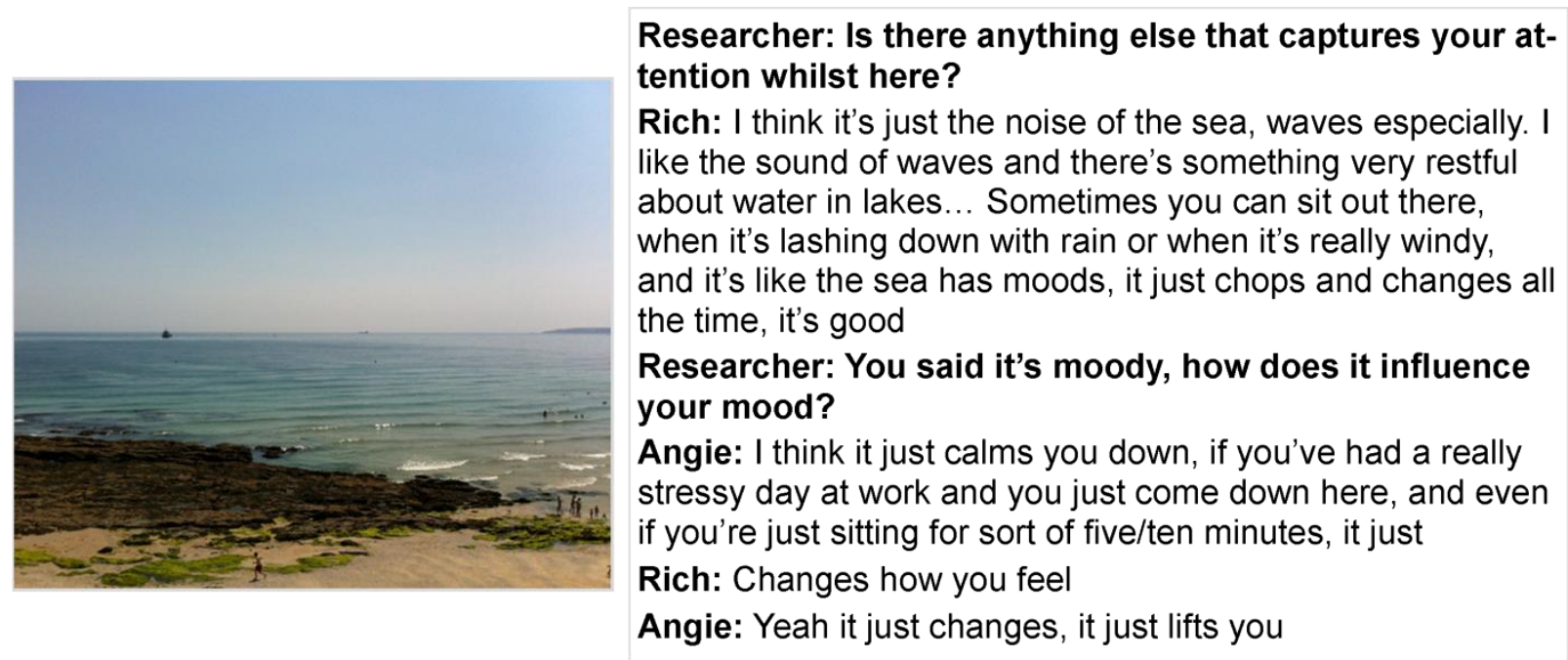

Moving beyond the "culturally sedimented model of the five senses" - sight, sound, taste, smell and touch - several participants illustrated the importance of internally felt bodily sensations at the coast (Paterson, 2009, p. 768), conveying the importance of 'haptic' restorative sensory experiences. In these narratives (e.g. Box 8, Figure 1), participants highlighted the feeling of the whole body reacting to different elements of the setting. This was in terms of the physicality of moving through the environment and the physical sensations of feeling the elements, including the sun, wind, rain or ambient temperature (termed 'elemental haptics' by Allen-Collinson and Leledaki, 2014). These findings illustrate the 'wholeness' of embodied restorative coastal encounters and suggest the need to appreciate the "fullness of our bodily sensibilities" (Ryan, 2012, p. 73) when exploring people's therapeutic landscape experiences.

In addition to the fluidity and ever-changing nature of the coast, participants also commented on the sense of space and time out engendered by the oceanic horizon (Figure 1, Box 5). The physical extent and broad horizons of the sea afforded a sense of spaciousness, which participants felt helped to 'clear the head', suggesting feelings of cognitive release or 'internal spaciousness' (Conradson, 2005). Participants often linked these experiences to feelings of freedom, appreciating the contrasts between 
such open horizons and the enclosed, indoor environments routinely encountered at home and work (Tuan, 1977).

For some participants, encountering these open horizons conferred a sense of perspective and feelings of connection to 'something bigger'. This is illustrated in the extract from Sally's interview below, in which she explains how engaging with nature during her weekly coastal walk puts her personal problems into perspective.

Researcher: What it is about that walk that helps you to switch off?

Sally: "You've got, you know, the fresh air, you've got, it's just space! I mean I think after living in London so many years, you're so enclosed. So to have that space and realise that there's a bigger thing out there than you, and nature is quite an amazing thing - when you look at the sky and the sea and the birds - just to kind of ((pause)) take it in, you know, and sometimes it's like, well maybe my problems aren't as bad as I perceive them to be, because you've got all of this around you, it kind of puts things into perspective if that makes sense?"

These narratives align with the deepest stage of contemplation in attention restoration theory gaining the opportunity to reflect on "life's larger questions", including one's "place in the overall scheme of things" (Herzog et al., 1997, p. 166). Such descriptions also have several parallels with a category of 'peak experiences' that have been described in the literature as 'diminutive experiences'. These are characterised by "feeling insignificant and humble while experiencing fascination with compelling elements of the environment" (Pomfret, 2012, p. 148). Much of the existing literature on these types of experiences originates from wilderness, outdoor adventure and nature-based tourism studies (McDonald et al., 2009; Pomfret and Bramwell, 2014). However, this study suggests that similar feelings of perspective can be conjured through 'everyday' coastal interactions (Game and Metcalfe, 2011; Kearns and Collins, 2013). 
Interestingly, for Mia during her go-along interview, these multiple scales of coastal engagement (from the intimate tactile sensation of sand between the toes to the outward appreciation of the sea's vast horizon) were sufficient to draw her attention away from a long-standing derelict coastal development site (Figure 1, Boxes 2, 9) that otherwise dominated much of the eastern part of the beach. Whilst plans are underway locally to re-develop the area, Mia feared that the related construction noise and subsequent influx of visitors to the beach would significantly compromise the sense of wellbeing she currently experiences along that stretch of coastline.

\subsection{Social therapeutic experiences at the coast}

Several participants discussed the importance of the social context and social relations linked to their preferred therapeutic experiences. These included three types of social dynamics, each of which were apparent within local coastal spaces: (a) seeking friendly conversation and a convivial atmosphere; (b) engaging with spaces offering varied opportunities for family leisure and wellbeing; and (c) connecting through shared hobbies and experiences.

Participants often indicated the value of impromptu conversations in public spaces (such as those between regular dog walkers, depicted in Mia's go-along interview in Figure 1, Box 6). These offered opportunities to make a positive but undemanding human connection. As described by Peters et al. (2010, p. 94), such interactions may be enjoyed by people "trying to pass the time by having a chat, sharing an unexpected experience, getting some information on a topic of interest or basking in the momentary glow of 'fellow feeling'". These types of interaction occur in 'third places' (Gardner, 2011), characterised as accessible, inclusive and with a positive social atmosphere.

Opportunities to feel part of a positive social ambience at the coast were discussed by a number of participants, as illustrated in Figure 3, in which Rachel describes her appreciation of the 'holiday buzz' experienced at a nearby World Heritage Site harbour village. She explains that, as a stay-at-home mum, she identifies with the holiday-makers there because they are rarely in a rush. They therefore 
display a "relaxed tendency", allowing for casual friendly interaction, or a "situated connectivity"

(Ryan, 2012, p. 200).

Figure 3. Seeking a positive social ambience at the coast

Rachel: "Oh yeah and that's the park. There were lots of people in there. We met some friends at Charlestown and walked round and then the children all played in the park"

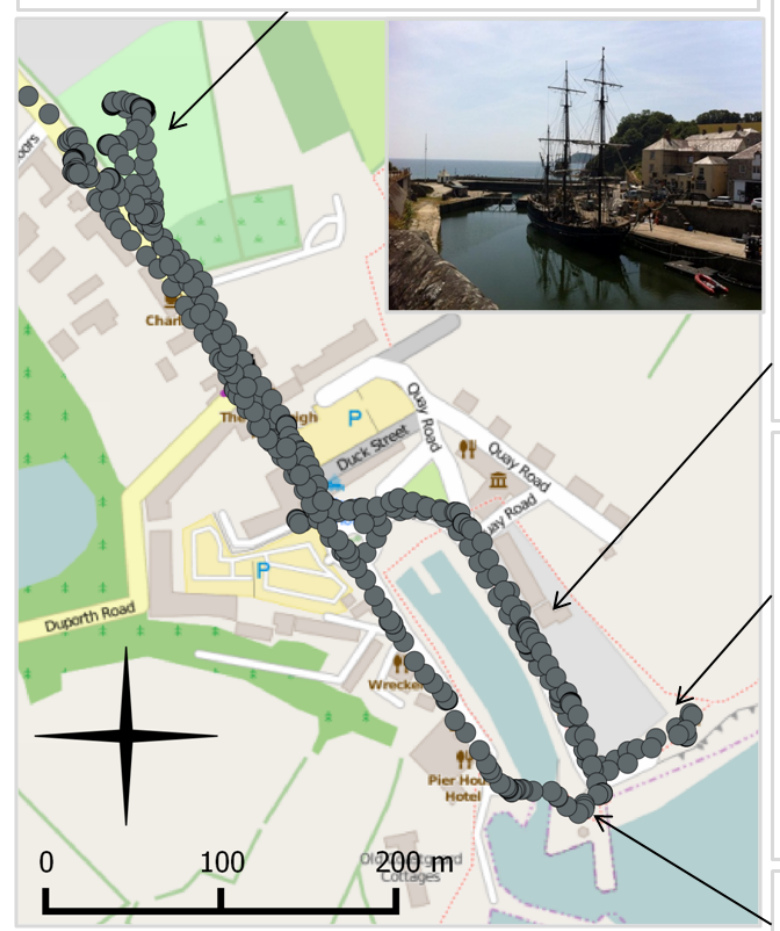

N.B. Due to accelerometer malfunction, Rachel's maps are based only on GPS data, with a dot plotted every 10 seconds. Based on a visit lasting approx 2 hrs. Base map: Data-CC-By-SA by OpenStreetMap
Rachel: "I just love it down there. There's just something so chilled out and everyone's on holiday so they exhibit that relaxed tendency... l've noticed a complete personality shift since becoming a mum... you've got weird pressures in the stress of getting them ready or being with them all the time... but you've got a lot of time and people on holiday also have a lot of time, so when we get somewhere there's no, we're not necessarily aiming to do anything so it's just nice to chat to people and be in that frame of mind whereas generally wherever you are, everyone is kind of 'I have got my agenda, I'm off on that ....I've got....' you know missions! ((laughs)) So I think that's the holiday feel that I like, it's just people have time to talk"

Rachel: "I think that night it was quite, um, intense waves. We couldn't get onto the beach, so we walked round that bit of it instead to see it, and watched the mad children. Like parents were letting their children in that - it was really crashing down! There's two walls aren't there at Charlestown, and it doesn't take much for a wave to crash you in. I mean I know you'd have gone down and you'd have got them out but they'd have still got a good bash on the head. So, anyway, yeah we watched from a distance! ((laughs))"

Rachel: "There's the little, we have to do the tunnel "cos my husband has to be the monster in the tunnel for the children ((laughs)). He has to run away!"

This positive social ambience appeared to stem from built, green and blue features of the area,

including the presence of the sea (despite its risk element - discussed further below), the coastal path, a park up the road where Rachel took her children to play, the historic interest of the harbour and its tall ships, and the numerous cafes encouraging people to linger in the area.

Importantly, there seemed to be a fine line between a positive social atmosphere and perceived crowding, with the issue of summer crowding mentioned by all participants. Whilst busyness does not 
always lead to perceived crowding (Tuan, 1977), participants' narratives indicated this to be more likely when desired activities conflict, as illustrated in the extract from Mike's interview below:

Mike: "In the summer it's just heaving... if we're just gonna pop to the beach, then we'll pop down and have a play and build castles and go in the rock pools, so you'll pick the small ones that holiday makers will just stumble on rather than know they're there. You go down there for a bit of quiet and a bit of peace and to have fun with the kids or the dogs, but if it's heaving with people then it becomes the opposite".

Several participants used adaptive strategies to minimise their sense of crowding during the holiday periods. These included: the avoidance of more commercialised beaches; walking further along the coast to quiet beaches with no facilities which tourists rarely locate; reverting to inland woodland rather than coastal walks which tend to be less busy; focusing on more local activities and reducing car use for leisure in order to avoid the increased road congestion; and making the most of preferred coastal areas out of season where possible.

Consistent with existing literature (Ashbullby et al., 2013), the role of the coast in promoting family wellbeing emerged across the accounts of several participants, particularly those with young children. The beach seemed to meet the needs of parents and children alike, providing (affordable) opportunities for both play and the types of immersive experiences discussed above (as touched on by Mia in Figure 1, Box 5). For example, Pete described family days at the beach as "the best ones", Dom referred to them as a "play fest" and Linda appreciated them as a "really unwinding day".

Participants looking for a positive family day out at the beach tended to prioritise safe, quiet beaches within close proximity to home, ideally sandy, with rock pools and calm water, without too strong a current. Upon becoming parents, participants conveyed a heightened sense of risk (see Figure 3) within places that they had previously considered important for their personal wellbeing (Reis et al., 
2012). As such, a trade-off was often made between the north coast beaches (preferred by some participants for their size, sand, and 'ruggedness') and the convenience and safety afforded by the south coast beaches. Illustrating a form of purposive family leisure (Shaw and Dawson, 2001), participants sought beaches perceived to cater for the needs, capabilities and interests of all the family rather than the individual.

Several participants indicated emotional attachments to specific local beaches where they had memories of time spent together as a family. This is illustrated in Figure 4, in which Bill explains the importance of a north coast beach, where fond memories and layers of meaning have accumulated through multiple family generations (Hebblethwaite, 2014). This process of ongoing meaning-making is seen as integral to the formation of lasting family bonds (Harrington, 2014).

Figure 4. Accumulating meaning through the family generations

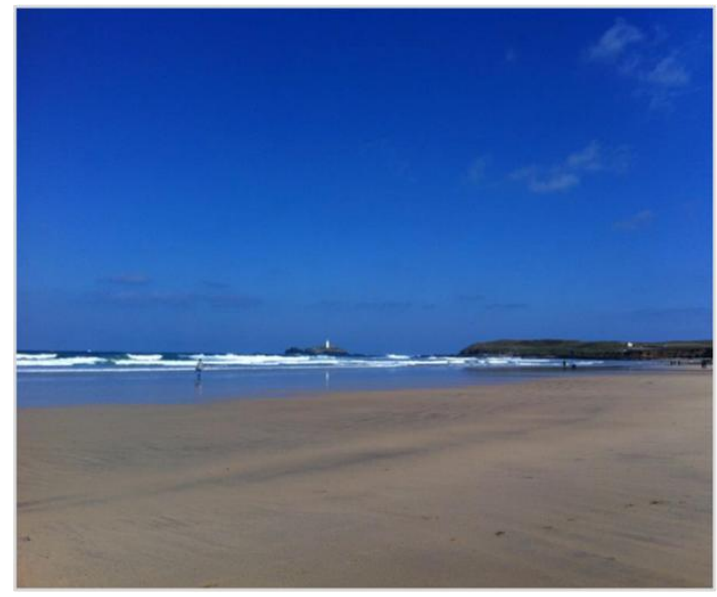

Bill (when asked why he's drawn to Gwithian): "Because it's our favourite place! We have a chalet at the back of Gwithian - it's been in the family for ages - that we have the use of. It's let through the summer to pay for itself but out of season we can just go up and stay. So we immediately go there, and Gwithian was where my other half was sort of brought up as a child so they used to just go when school finished. They would pack up and go to Gwithian and stay there until the end of the summer holidays and go back, so you know, it's very much a sort of second home, home-fromhome sort of place really"

Processes of meaning-making and the importance of shared therapeutic experiences were also apparent in participants' narratives of time spent in specific coastal areas with their partners, close friends or grown-up children. The presence of valued company during these experiences allowed moments of quiet comfortable companionship to be interspersed with easy conversation. This contributed to a shared or 'relational' sense of wellbeing (Doughty, 2013), creating deeper feelings of connection, both to each other and to the places/activities in question. This is illustrated in Figure 5

Post-review pre-print. Published as:

Bell, SL., Phoenix, C., Lovell, R. and Wheeler, BW. (2015) Seeking everyday wellbeing: The coast as a therapeutic landscape. Social Science \& Medicine, 142: 56-67. 
below, in which Pete describes one of his weekly canoeing trips around the south coast with his wife, Jenny, explaining where they sped up, slowed down or lingered. The soothing sound of raindrops hitting the water surface, coupled with the lack of other distractions, allowed them a rare opportunity to fully relax together. As Pete commented later, they appreciate canoeing as it serves to both "keep you fit and calm you down at the same time".

\section{Figure 5. A shared canoe trip on the south coast}

Pete: We went from the car park, hence the very slow walk down with the canoe ((laughs)) and then over to Portholland where our son was on the beach with his cubs, "cos they had the day there. And then we went out around the corner here to see what was round there. Where it's all plotted together back about here, that's where Jenny fell asleep ((laughs))... It started to rain so we stopped for a while and just listened to the rain on the water. It was very calming. Then you come back and there's a little beach just there, which you can't get to except for on a boat. Then went round to explore all the little coves around this side. We stopped again there and she fell asleep again ((laughs)) It's the only time that she'll relax, she'll be asleep!

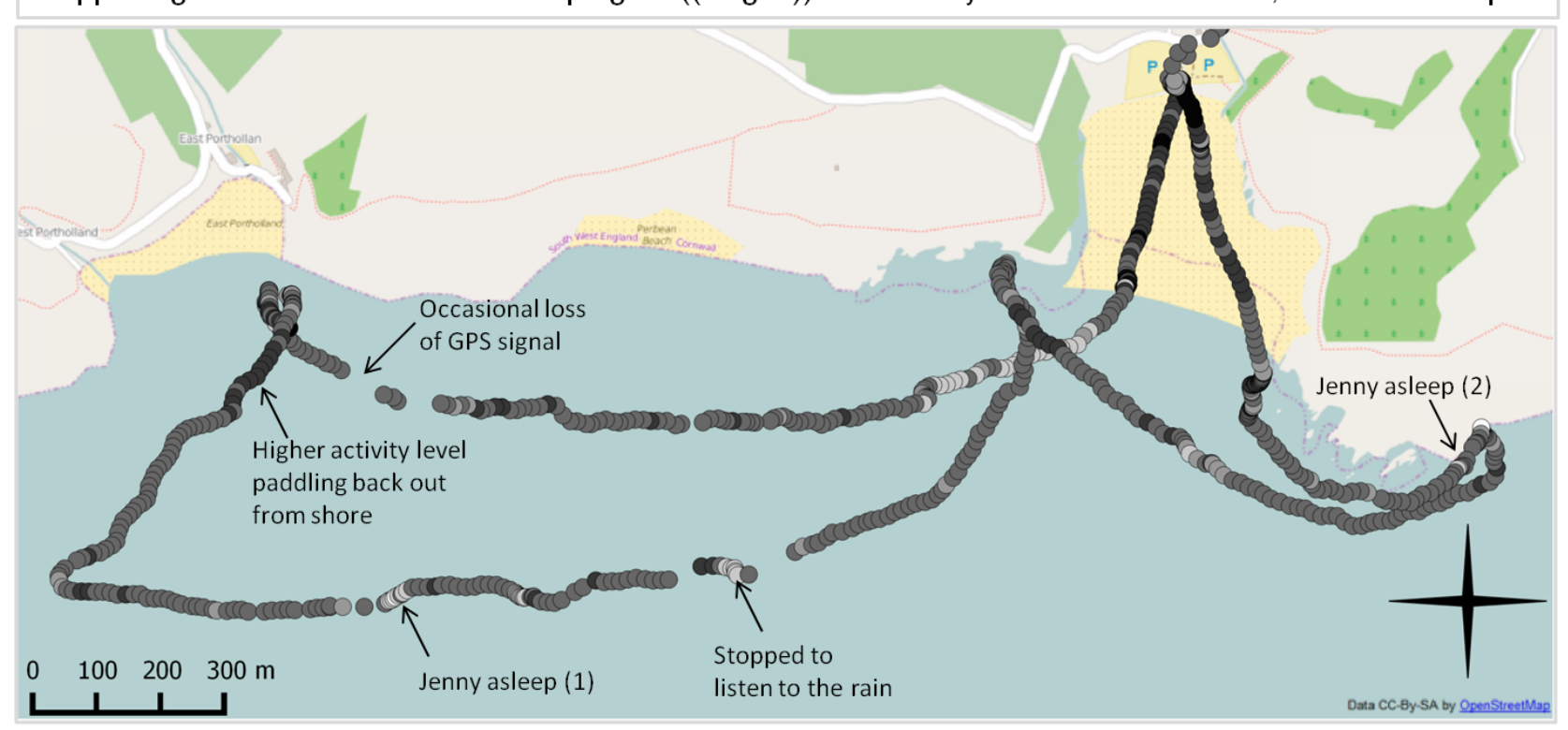

N.B. A dot is plotted every 10 seconds (provided the GPS could detect signal). The colour of the dot corresponds to the relative activity level detected by the accelerometer, whilst the location of the dot is determined by the associated GPS reading. Darker coloured dots indicate relatively greater accelerations per 10 s time period (i.e. participants were being more active). The greater the distance between the dots, the faster the GPS unit was travelling. This canoe trip lasted approx. five hours.

Whilst it has been suggested that social company could compromise individual green space experiences (Edensor, 2000), the findings of this study indicate that the presence of people perceived to share similar values and preferences may enhance opportunities for positive therapeutic experiences. Amongst these study participants, this occurred through providing support, facilitating a 
mutually comfortable and enjoyable experience, and developing positive inter-subjective place meanings. As noted by Smaldone et al. (2005), public spaces become meaningful as 'containers' of important social relationships and shared experiences specific to different life events and stages. The opportunity for social contact has been proposed as a potential mechanism for nature-health relationships (Hartig et al., 2014), but the complexity illustrated here may help to explain the mixed findings of the population-level evidence for this social mechanism to-date.

\section{Summary: an interdisciplinary model of therapeutic landscape experiences at the coast}

In this final discussion section, we present an interdisciplinary model (Figure 6) that summarises the therapeutic landscape experience dimensions (and associated theoretical constructs) presented above in order to provide greater understanding of the diverse ways in which participants were able to experience a sense of wellbeing through their local coastal interactions. In doing so, it integrates a number of relevant diverse literatures and builds on the most recent therapeutic landscapes framework suggested by Völker and Kistemann (2013). This emphasised the importance of symbolic, activity, experienced and social space dimensions in the context of urban riverside settings.

This interdisciplinary model focuses primarily on the types of experiences sought out (rather than specific place features) in order to show the varied ways in which people may choose to engage with the coast for wellbeing. It also conveys the varied scales of these encounters, from views of the sea's expanse to intimate tactile sensations of the body coming into contact with the elements. The model seeks to advance our understanding of how and why coastal spaces are experienced as therapeutic by highlighting important overlaps with other theories relevant to our understanding of the links between blue space, health and wellbeing (e.g. sense of place, attention restoration, flow, peak experience etc). Moreover, it highlights notions of personal challenge and achievement which, although recognised as important components of eudaimonic wellbeing (Reid and Hunter, 2011), are rarely discussed in the context of therapeutic landscape experiences. 
Figure 6. Four overlapping therapeutic experience dimensions (building on Völker and Kistemann, 2013)

Restorative immersive experiences: sense of space; opportunities to explore; captivating multisensory spaces; relaxing place rhythms

(e.g. coastal path, beaches)

Immersive inspiring experiences:

Flow: peak and micro, influenced by ambient conditions (e.g. whilst sailing, surfing, sea fishing)

Long-term achievements \& more immediate gratification: Pursuing internal states of physical fitness and other personally meaningful goals; short-term cognitive release through physicality in a pleasurable setting (e.g. Whilst in the water, beside the coast, and/orwith coastal views) settings for mutual hobbies (e.g. kayaking clubs, surfing community)

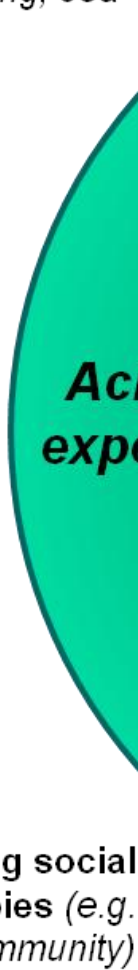

\section{Immersive}

\section{experiences}

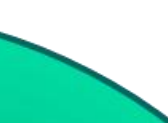
expanse, power and perspective; diminutive peak experiences; sense of freedom; simple pleasures (e.g. expanse and broad horizons over the sea, power of the waves

Cultural/personal place meanings: existing cultural/political place narratives (e.g. Romantic conceptions of the coast); personal sense of place including feelings of belonging, identity, rootedness, attachment (e.g. specific views, coastal proximity)

Shared place meanings: places as containers of important relationships and shared experiences over time (e.g. early courtship/marriage/engagement settings, family leisure traditions)

Social experiences: opportunities for a conversation; engaging in a convivial social ambience without feelings of crowding; comfortable companionship and a shared sense of wellbeing; family leisure (e.g. harbours, 


\section{Conclusions}

Complementing the large body of literature on green space and wellbeing (recently reviewed by Hartig et al., 2014), this article has explored the diverse coastal experiences sought out by residents of two towns in south west England to promote and preserve their wellbeing in the context of their everyday lives. In doing so, it has advanced our understanding of the varied therapeutic experiences contributing to participants' sense of wellbeing in their local coastal environments, incorporating symbolic, achieving, immersive and social dimensions. Although valuable findings emerged from the study regarding the therapeutic nature of participants' wider green and blue space encounters, this paper focused specifically on the coast. This is due in part to the greater frequency and depth at which coastal encounters were discussed by participants, but also to the heightened awareness of spatial experience that was apparent within many participants' coastal narratives (Ryan, 2012).

Whilst the specific coastal interactions sought out by participants varied, the diversity of the local coastline seemed to provide opportunities for a broad range of therapeutic experiences, at multiple scales and intensities. Different stretches were able to cater for those looking for emotional, active, immersive, tranquil, and/or social (be it with strangers, friends, partners or family) experiences. However, participants also noted shifts in their use of the coast over time. These were both temporary (e.g. to avoid summer crowding or particularly wet/cold weather) and longer lasting (e.g. seeking more child-friendly, lower-risk coastal areas in parenthood).

The findings presented here support calls (e.g. by Kearns and Collins, 2013) to account for people's emotional and embodied connections to the coast within coastal management policy and practice. The multiple and nuanced ways in which people engage with coastal spaces for wellbeing suggest the need to nurture diversity along the coastline, catering for wide-ranging needs and interests to minimise sensations of crowding and maximise opportunities for individuals, families, couples and

\section{Post-review pre-print. Published as:}

Bell, SL., Phoenix, C., Lovell, R. and Wheeler, BW. (2015) Seeking everyday wellbeing: The coast as a therapeutic landscape. Social Science \& Medicine, 142: 56-67. 
friends to experience a sense of wellbeing. Such efforts should recognise, however, the fluid, reciprocal nature of the land-sea boundary (Ryan, 2012) - and the immersive therapeutic experiences linked to this fluidity - rather than viewing it as rigid and fixed. This is particularly important in light of the increasing pressures exerted on our coastlines, both from human users and from physical risks associated with climate change and rising sea levels.

The study has provided rich, in-depth insights into the therapeutic potential of different types of coastal experiences. However, these insights are based on a small self-selected sample, and the findings may have varied had different individuals been recruited from within the study sites or further afield. For example, would individuals with sensory impairments - who may be unable to engage in the embodied, multi-sensory immersive experiences valued by participants in this study still perceive such therapeutic potential at the coast? How might perceptions vary with different types of coastline (e.g. more developed or visibly managed coastlines)? A recent study identified significant regional differences in population-level associations between coastal proximity and physical activity in England (White et al., 2014), suggesting the need for deeper understanding of the different ways in which people relate to their local coastlines and why. With this in mind, future research could usefully combine in-depth studies examining the needs and coastal experiences of specific population groups with larger-scale surveys aimed at understanding the scale and range of the emerging insights.

Longitudinal studies would be particularly valuable in tracking the influence of different life transitions on the perceived importance of coastal environments for wellbeing over time. For example, as noted above, one participant compared the turquoise colour of the sea encountered along parts of the Cornish coastline with the 'grey sludge' she had seen at the coast elsewhere in England earlier in her life. This raises interesting questions regarding the influence of personal place histories in shaping the therapeutic potential perceived in different places. For example, how does experience of one type of coastline influence perceptions of another? How does past exposure to contrasting cultural practices

\section{Post-review pre-print. Published as:}

Bell, SL., Phoenix, C., Lovell, R. and Wheeler, BW. (2015) Seeking everyday wellbeing: The coast as a therapeutic landscape. Social Science \& Medicine, 142: 56-67. 
at the coast, or experiences of exclusion (e.g. due to ethnicity, race, income), influence personal norms of use? What could be learned from comparative studies across international settings about the role of culture in shaping human perceptions of, and the meanings attributed to, coastal experiences?

These diverse lines of enquiry are important for future research in this emergent field, enhancing our understanding of the specific therapeutic potential of blue spaces in comparison to solely green spaces (e.g. motion and sounds of water, specific cultural connotations) for different individuals over time.

\section{Acknowledgements}

The authors would like to thank the European Social Fund Convergence Programme for Cornwall and the Isles of Scilly for funding Sarah Bell's PhD scholarship, as well as Westley Design; a landscape architecture and inclusive design consultancy which has provided valuable practical insights and guidance to the design of this doctoral research project. Thanks also go to the three anonymous referees for their valuable feedback on an earlier draft of this article.

The European Centre for Environment and Human Health (part of the University of Exeter Medical School) is part financed by the European Regional Development Fund Programme 2007 to 2013 and European Social Fund Convergence Programme for Cornwall and the Isles of Scilly.

\section{References}

Allen-Collinson, J. \& Leledaki, A. (2014). Sensing the outdoors: a visual and haptic phenomenology of outdoor exercise embodiment. Leisure Studies, 34, 457-470.

Andrews, G. \& Kearns, R. (2005). Everyday health histories and the making of place: the case of an English coastal town. Social Science and Medicine, 60, 2697-2713. 
Ashbullby, K. J., Pahl, S., Webley, P. \& White, M. (2013). The beach as a setting for families' health promotion: a qualitative study with parents and children living in coastal regions in Southwest England. Health and Place, 23, 138-147.

Bauman, A., Smith, B., Stoker, L., Bellew, B. \& Booth, M. (1999). Geographical influences upon physical activity participation: evidence of a 'coastal effect'. Australian and New Zealand Journal of Public Health, 23.

Beedie, P. (2014). Playing in the great outdoors: risk and adventure activities in the twenty-first century. In S. Elkington. \& S. Gammon (Eds.), Contemporary perspectives in leisure: Meanings, motives and lifelong learning (pp. 79-92). Abingdon: Routledge.

Bell, SL., Phoenix, C., Lovell, R. and Wheeler, BW. (2015) Using GPS and geo-narratives: a methodological approach for understanding and situating everyday green space encounters. Area, 47, 88-96.

Braubach, M. (2007). Preventive applications of the therapeutic landscapes concept in urban residential settings: a quantitative application. In A. Williams (ed), Therapeutic Landscapes (pp. 111-132). Surrey: Ashgate Publishing Ltd.

Cattell, V., Dines, N., Gesler, W. \& Curtis, S. (2008). Mingling, observing, and lingering: Everyday public spaces and their implications for wellbeing and social relations. Health and Place, 14, 544-561.

Collins, D. \& Kearns, R. (2007). Ambiguous landscapes: sun, risk and recreation on New Zealand beaches. In A. Williams (Ed.), Therapeutic Landscapes (pp. 15-32). Surrey: Ashgate Publishing Ltd.

Conradson, D. (2005). Landscape, care and the relational self: Therapeutic encounters in rural England. Health and Place, 11, 337-348. 
Cosgriff, M., Little, D. \& Wilson, E. (2009). The nature of nature: how New Zealand women in middle to later life experience nature-based leisure. Leisure Sciences, 32, 15-32.

Csikszentmihalyi, M. (2002). Flow. London, Rider.

De Vries, S., Verheij, R., Groenewagen, P. \& Spreeuwenberg, P. (2003). Natural environments - healthy environments? An exploratory analysis of the relationship between greenspace and health. Environment and Planning A, 35, 1717-1731.

Dinnie, E., Brown, K. \& Morris, S. (2013). Community, cooperation and conflict: Negotiating the social well-being benefits of urban greenspace experiences. Landscape and Urban Planning, 112, 1-9.

Doughty, K. (2013). Walking together: The embodied and mobile production of a therapeutic landscape. Health and Place, 24, 140-146.

Edensor, T. (2000). Walking in the British Countryside: Reflexivity, embodied practices and ways to escape. Body and Society, 6, 81-106.

Eyles, J. \& Williams, A. (2008). Introduction. In J. Eyles. \& A. Williams (Eds.), Sense of Place, Health and Quality of Life (pp. 1-14). Hampshire: Ashgate Publishing Ltd.

Foley, R. (2011). Performing health in place: The holy well as a therapeutic assemblage. Health and Place, $17,470-479$.

Fox, R. \& Lloyd, W. (1938). Convalescence on the coast. The Lancet, 232, 37-39.

Game, A. \& Metcalfe, A. (2011). 'My corner of the world': Bachelard and Bondi Beach. Emotion, Space and Society, 4, 42-50.

Gardner, P. (2011). Natural neighbourhood networks - Important social networks in the lives of older adults aging in place. Journal of Aging Studies, 25, 263-271.

\section{Post-review pre-print. Published as:}

Bell, SL., Phoenix, C., Lovell, R. and Wheeler, BW. (2015) Seeking everyday wellbeing: The coast as a therapeutic landscape. Social Science \& Medicine, 142: 56-67. 
Gesler, W. (1992). Therapeutic landscapes: Medical Issues in the light of the new cultural geography. Social Science and Medicine, 34, 735-746.

Gesler, W. (1996). Lourdes: healing in a place of pilgrimage. Health and Place, 2, 95-105.

Gesler, W. (2003). Healing Places. Maryland: Rowman \& Littlefield Publishers Inc.

Harrington, M. (2014). Practices and meaning of purposive family leisure among working- and middleclass families. Leisure Studies.

Hartig, T., Mitchell, R., De Vries, S. \& Frumkin, H. (2014). Nature and Health. Annual Review of Public Health, 35, 207-228.

Hebblethwaite, S. (2014). "Grannie's got to go fishing": meanings and experiences of family leisure for three-generation families in rural and urban settings. World Leisure Journal, 56, 42-61.

Herzog, T., Black, A., Fountaine, K. \& Knotts, D. (1997). Reflection and attentional recovery as distinctive benefits of restorative environments. Journal of Environmental Psychology, 17, 165170.

Huber, M., Knottnerus, J., Green, L., van der Horst, H., Jadad, A.R., Kromhout, D., Leonard, B... Smid, H. (2011). How should we define health? BMJ, 343, 4163-4165.

Humberstone, B. (2013). Adventurous activities, embodiment and nature: spiritual, sensual and sustainable? Embodying environmental justice. Motriz: Revista de Educação Física, 19, 565571.

Kaplan, S. (1995). The restorative benefits of nature: Toward an integrative framework. Journal of Environmental Psychology, 15, 169-182.

Kearns, R. \& Collins, D. (2013). Feeling for the coast: the place of emotion in resistance to residential development. Social \& Cultural Geography, 13, 937-955.

Post-review pre-print. Published as:

Bell, SL., Phoenix, C., Lovell, R. and Wheeler, BW. (2015) Seeking everyday wellbeing: The coast as a therapeutic landscape. Social Science \& Medicine, 142: 56-67. 
Krenichyn, K. (2006). 'The only place to go and be in the city': women talk about exercise, being outdoors, and the meanings of a large urban park. Health and Place, 12, 631-643.

Kwan, M. \& Ding, G. (2008). Geo-narrative: Extending Geographic Information Systems for Narrative Analysis in Qualitative and Mixed-Method Research. The Professional Geographer, 60, $443-$ 465.

Kyle, G., Mowen, A. \& Tarrant, M. (2004). Linking place preferences with place meaning: an examination of the relationship between place motivation and place attachment. Journal of Environmental Psychology, 24, 439-454.

Leach, D. (1963). Meaning and correlates of peak experience. Dissertation Abstracts, 24, 180.

Lenček, L. \& Bosker, G. (1998). The Beach: The history of paradise on earth. London: Secker and Warburg, Random House.

Maas, J., Verheij, R., Groenewegen, P., De Vries, S. \& Spreeuwenberg, P. (2006). Green space, urbanity, and health: how strong is the relation? Journal of Epidemiology and Community Health, 60, 587-592.

McDonald, M., Wearing, S. \& Ponting, J. (2009). The Nature of Peak Experience in Wilderness. The Humanistic Psychologist, 37, 370-385.

Milligan, C., Bingley, A. \& Gatrell, A. (2005). 'Healing and Feeling': The place of emotions in later life. In J. Davidson, L. Bondi. \& M. Smith (Eds.), Emotional Geographies (pp. 49-62). Surrey: Ashgate Publishing Ltd.

Milligan, C. \& Bingley, A. (2007). Restorative places or scary spaces? The impact of woodland on the mental wellbeing of young adults. Health and Place, 13, 799-811.

Post-review pre-print. Published as:

Bell, SL., Phoenix, C., Lovell, R. and Wheeler, BW. (2015) Seeking everyday wellbeing: The coast as a therapeutic landscape. Social Science \& Medicine, 142: 56-67. 
Paterson, M. (2009). Haptic geographies: ethnography, haptic knowledges and sensuous dispositions. Progress in Human Geography, 33, 766-788.

Phoenix, C. \& Orr, N. (2014). Pleasure: A forgotten dimension of physical activity in older age. Social Science \& Medicine, 115, 94-102.

Pomfret, G. (2012). Personal emotional journeys associated with adventure activities on packaged mountaineering holidays. Tourism Management Perspectives, 4, 145-154.

Pomfret, G. \& Bramwell, B. (2014). The characteristics and motivational decisions of outdoor adventure tourists: a review and analysis. Current Issues in Tourism.

Privette, G. (1983). Peak Experience, Peak Performance, and Flow: A comparative analysis of positive human experiences. Journal of Personality and Social Psychology, 45, 1361-1368.

Reid, L. \& Hunter, C. (2011). Personal wellbeing and interactions with nature. BeWEL State of Understanding Report 1. Prepared for the ESRC. Retrieved from http://www.esrc.ac.uk/myesrc/grants/RES-355-25-0020/outputs/read/37df7aac-3f04-4e7d-b68c-663cee662fb0

Reis, A., Thompson-Carr, A. \& Lovelock, B. (2012). Parks and families: addressing management facilitators and constraints to outdoor recreation participation. Annals of Leisure Research, 15, 315-334.

Ryan, A. (2012). Where Land Meets Sea: Coastal Explorations of Landscape, Representation and Spatial Experience. Surrey: Ashgate Publishing Ltd.

Shaw, S. \& Dawson, D. (2001). Purposive Leisure: Examining parental discourses on family activities. Leisure Sciences, 23, 217-231.

Smaldone, D., Harris, C. \& Sanyal, N. (2005). An exploration of place as a process: the case of Jackson Hole, WY. Journal of Environmental Psychology, 25, 397-414.

Post-review pre-print. Published as:

Bell, SL., Phoenix, C., Lovell, R. and Wheeler, BW. (2015) Seeking everyday wellbeing: The coast as a therapeutic landscape. Social Science \& Medicine, 142: 56-67. 
Smyth, F. (2005). Medical geography: therapeutic places, spaces and networks. Progress in Human Geography, 29, 488-495.

Tracy, S. (2010). Qualitative Quality: Eight "Big-Tent" criteria for excellent qualitative research. Qualitative Inquiry, 16, 837-850.

Tuan, Y-F. (1974). Topophilia. New York: Columbia University Press.

Tuan, Y-F. (1977). Space and Place: The perspective of experience. Minneapolis: University of Minnesota Press.

Tuan, Y-F. (1980). Rootedness versus sense of place. Landscape, 24, 3-8.

Völker, S. \& Kistemann, T. (2011). The impact of blue space on human health and well-being Salutogenic health effects of inland surface waters: A review. International Journal of Hygiene and Environmental Health, 214, 449-460.

Völker, S. \& Kistemann, T. (2013). "I'm always entirely happy when I'm here!" Urban blue enhancing human health and well-being in Cologne and Düsseldorf, Germany. Social Science \& Medicine, 78, 113-124.

Walton, J. (2000). The British Seaside: Holidays and resorts in the twentieth century. Manchester: Manchester University Press.

Wakefield, S. \& McMullan, C. (2005). Healing in places of decline: (re)imagining everyday landscapes in Hamilton, Ontario. Health and Place, 11, 299-312.

Wheeler, B., White, M., Stahl-Timmins, W. \& Depledge, M. (2012). Does living by the coast improve health and wellbeing? Health and Place, 18, 1198-1201.

Post-review pre-print. Published as:

Bell, SL., Phoenix, C., Lovell, R. and Wheeler, BW. (2015) Seeking everyday wellbeing: The coast as a therapeutic landscape. Social Science \& Medicine, 142: 56-67. 
White, M., Smith, A., Humphryes, K., Pahl, S., Snelling, D. \& Depledge, M. (2010). Blue space: the importance of water for preference, affect, and restorativeness ratings of natural and built scenes. Journal of Environmental Psychology, 30, 482-493.

White, M., Alcock, I., Wheeler, B. \& Depledge, M. (2013a). Coastal proximity, health and well-being: Results from a longitudinal panel survey. Health and Place, 23, 97-103.

White, M., Pahl, S., Ashbullby, K., Herbert, S. \& Depledge, M. (2013b). Feelings of restoration from recent nature visits. Journal of Environmental Psychology, 35, 40-51.

White, M., Wheeler, B., Herbert, S., Alcock, I. \& Depledge, M. (2014). Coastal proximity and physical activity: Is the coast an under-appreciated public health resource? Preventive Medicine, 69, 135-140.

Williams, A. (2007). Introduction: The Continuing Maturation of the Therapeutic Landscape Concept. In A. Williams (Ed.), Therapeutic Landscapes (pp. 1-12). Surrey: Ashgate Publishing Ltd.

Williams, A. (2010). Spiritual therapeutic landscapes and healing. A case study of St. Anne de Beaupre, Quebec, Canada. Social Science and Medicine, 70, 1633-1640.

Willis, A. (2009). Restorying the self, restorying the place: healing through grief in everyday places. Emotion, Space and Society, 2, 86-91.

Witten, K., Hiscock, R., Peace, J. \& Blakely, T. (2008). Neighbourhood access to open spaces and the physical activity of residents: a national study. Preventive Medicine, 47, 299-303.

Post-review pre-print. Published as:

Bell, SL., Phoenix, C., Lovell, R. and Wheeler, BW. (2015) Seeking everyday wellbeing: The coast as a therapeutic landscape. Social Science \& Medicine, 142: 56-67. 
Appendix A. Supplementary data: Study participant profiles

\begin{tabular}{|c|c|c|c|c|c|c|}
\hline Pseudonym & $\begin{array}{c}\text { Age } \\
\text { bracket/ } \\
\text { yrs }\end{array}$ & $\begin{array}{l}\text { Employment } \\
\text { status }\end{array}$ & $\begin{array}{c}\text { Relationship } \\
\text { status }\end{array}$ & Children & $\begin{array}{c}\text { Household } \\
\text { income } \\
\text { bracket/fk }\end{array}$ & $\begin{array}{l}\text { Duration in } \\
\text { study site }\end{array}$ \\
\hline \multicolumn{7}{|l|}{ Study Site 1} \\
\hline Tess & $35-44$ & Part time & Married & $\begin{array}{c}2 \\
(1.5,4 y r s)\end{array}$ & $50-69$ & $\begin{array}{c}<5 y r s \\
\text { (+ elsewhere } \\
\text { in Cornwall) }\end{array}$ \\
\hline $\begin{array}{c}\text { Meg } \\
* \text { int w/child }\end{array}$ & $35-44$ & Part time & Married & $\begin{array}{c}1 \\
\text { (16months + } \\
\text { expecting) }\end{array}$ & $30-39$ & $5-10$ yrs \\
\hline Elaine & $45-54$ & Non-working & Married & $\begin{array}{c}2 \\
(10,13 \mathrm{yrs})\end{array}$ & $70+$ & $5-10$ yrs \\
\hline Maggie & $45-54$ & $\begin{array}{l}\text { Unable to work } \\
\text { since accident }\end{array}$ & Married & $\begin{array}{c}1 \\
(19 \mathrm{yrs})\end{array}$ & $50-69$ & Since birth \\
\hline $\begin{array}{c}\text { Rich } \\
* \text { int w/wife }\end{array}$ & $45-54$ & Full time & $\begin{array}{c}\text { Married (to } \\
\text { Angie) }\end{array}$ & $\begin{array}{c}2 \\
(18,22 \text { yrs })\end{array}$ & $40-49$ & $<5$ yrs \\
\hline Angie & $45-54$ & Part time & $\begin{array}{l}\text { Married (to } \\
\text { Rich) }\end{array}$ & $\begin{array}{c}2 \\
(18,22 \mathrm{yrs})\end{array}$ & $40-49$ & $<5$ yrs \\
\hline Debbie & $55-64$ & Part time & Married & $\begin{array}{c}4 \\
(19,29,33,35 \\
y r s)\end{array}$ & $30-39$ & $5-10 y r s$ \\
\hline Anne & $55-64$ & Retired & Married & $\begin{array}{c}1 \text { child } \\
(34 \mathrm{yrs})\end{array}$ & $<20$ & Since birth \\
\hline Bill & $55-64$ & Partially retired & Married & $\begin{array}{c}2 \\
(23,25 y r s)\end{array}$ & $<20$ & $25-30$ yrs \\
\hline $\mathrm{Jim}$ & $65-74$ & Retired & Married & $\begin{array}{c}4 \\
(37,4546,48)\end{array}$ & $20-29$ & $20-25$ yrs \\
\hline Grace & $65-74$ & Retired & Bereaved & $\begin{array}{c}2 \\
(36,37 \mathrm{yrs})\end{array}$ & $<20$ & $15-20 \mathrm{yrs}$ \\
\hline Derek & $75+$ & Retired & Bereaved & $\begin{array}{c}2 \\
(48,51 \mathrm{yrs})\end{array}$ & $30-39$ & $15-20$ yrs \\
\hline \multicolumn{7}{|l|}{ Study Site 2} \\
\hline Amy & $25-34$ & Part time & $\begin{array}{l}\text { Not in a } \\
\text { relationship }\end{array}$ & 0 & $<20$ & Since birth \\
\hline $\begin{array}{c}\text { Zoe } \\
* \text { int w/child }\end{array}$ & $25-34$ & Self employed & Married & $\begin{array}{c}1 \\
\text { (9 months) }\end{array}$ & $20-29$ & $<5$ yrs \\
\hline Rachel & $25-34$ & Part time & Married & $\begin{array}{c}2 \\
(1,3 y r s)\end{array}$ & $40-49$ & $5-10 y r s$ \\
\hline Danny & $25-34$ & Full time & Married & $\begin{array}{c}2 \\
(8,13 y r s)\end{array}$ & $40-49$ & Since birth \\
\hline $\begin{array}{c}\text { Mike } \\
*_{\text {int }} \\
\text { w/children }\end{array}$ & $25-34$ & Full time & Married & $\begin{array}{c}2 \\
(5,8 \mathrm{yrs})\end{array}$ & $20-29$ & Since birth \\
\hline Owen & $25-34$ & Between jobs & $\begin{array}{l}\text { Lives with } \\
\text { partner }\end{array}$ & $\begin{array}{c}\text { Partner has } 2 \\
\text { children }(6,9 \\
\text { yrs) }\end{array}$ & $<20$ & $\begin{array}{c}1 \mathrm{yr} \\
\text { (+ elsewhere } \\
\text { in Cornwall) }\end{array}$ \\
\hline
\end{tabular}

Post-review pre-print. Published as:

Bell, SL., Phoenix, C., Lovell, R. and Wheeler, BW. (2015) Seeking everyday wellbeing: The coast as a therapeutic landscape. Social Science \& Medicine, 142: 56-67. 


\begin{tabular}{|c|c|c|c|c|c|c|}
\hline Adam & $35-44$ & Full time & Married & $\begin{array}{c}2 \\
(6,9 \mathrm{yrs})\end{array}$ & $50-69$ & Since birth \\
\hline Pete & $35-44$ & Full time & Married & $\begin{array}{c}2 \\
(6,9 \mathrm{yrs})\end{array}$ & $30-39$ & Since birth \\
\hline Dom & $35-44$ & Full time & Married & $\begin{array}{c}2 \\
(4,6 \mathrm{yrs})\end{array}$ & $50-69$ & Since birth \\
\hline $\begin{array}{c}\text { Dean } \\
* \text { int w/child }\end{array}$ & $35-44$ & Part time & $\begin{array}{l}\text { Lives with } \\
\text { partner }\end{array}$ & $\begin{array}{c}1 \\
\text { (mid-teens) }\end{array}$ & $20-29$ & $5-10$ yrs \\
\hline Sally & $35-44$ & Full time & $\begin{array}{l}\text { Not in a } \\
\text { relationship }\end{array}$ & 0 & $20-29$ & $10-15$ yrs \\
\hline Yvette & $45-54$ & Full time & Married & Expecting & $30-39$ & $\begin{array}{c}<5 \text { yrs } \\
\text { (+ elsewhere } \\
\text { in Cornwall) }\end{array}$ \\
\hline Tara & $45-54$ & Full time & $\begin{array}{l}\text { Not in a } \\
\text { relationship }\end{array}$ & 0 & $\begin{array}{l}\text { Household } \\
\text { income: } \\
\text { f20-29k }\end{array}$ & $<5$ yrs \\
\hline Mia & $45-54$ & Between jobs & $\begin{array}{l}\text { Not in a } \\
\text { relationship } \\
\text { (divorced) }\end{array}$ & $\begin{array}{c}2 \\
\text { (ages not given, } \\
\text { both grown up) }\end{array}$ & $<20$ & $\begin{array}{c}<5 \text { yrs } \\
\text { (+ elsewhere } \\
\text { in Cornwall) }\end{array}$ \\
\hline Liz & $45-54$ & Full time & Married & 0 & $20-29 k$ & $\begin{array}{c}5-10 \text { yrs } \\
\text { (+ elsewhere } \\
\text { in Cornwall) }\end{array}$ \\
\hline Lisa & $45-54$ & Full time & Married & 0 & $20-29$ & $10-15$ yrs \\
\hline Helen & $55-64$ & Full time & Married & $\begin{array}{c}3 \\
(22,24,26 y r s)\end{array}$ & $40-49$ & $<5$ yrs \\
\hline Hannah & $55-64$ & Part time & Married & $\begin{array}{c}2 \\
\text { (ages not given, } \\
\text { both grown up) }\end{array}$ & $<20$ & $\begin{array}{c}5-10 \text { yrs } \\
\text { (+ elsewhere } \\
\text { in Cornwall) }\end{array}$ \\
\hline Mack & $55-64$ & Full time & Married & $\begin{array}{l}3 \\
\text { (ages not given, } \\
\text { all grown up) }\end{array}$ & $20-29$ & $\begin{array}{l}15-20 \text { yrs } \\
\text { (+ born in } \\
\text { Cornwall) }\end{array}$ \\
\hline Linda & $55-64$ & Partially retired & Married & $\begin{array}{c}4 \\
(28,30,37,39 \\
\text { yrs })\end{array}$ & $<20$ & $40-50$ yrs \\
\hline $\begin{array}{c}\text { Ron } \\
\text { *int w/wife }\end{array}$ & $75+$ & Retired & Married & $\begin{array}{c}2 \\
(48,51 \mathrm{yrs})\end{array}$ & $20-29$ & $\begin{array}{l}50+\text { yrs } \\
\text { (+ born in } \\
\text { Cornwall) }\end{array}$ \\
\hline
\end{tabular}

* int w/child or wife/husband is used to denote that these relations were present during the geonarrative interview

\section{Post-review pre-print. Published as:}

Bell, SL., Phoenix, C., Lovell, R. and Wheeler, BW. (2015) Seeking everyday wellbeing: The coast as a therapeutic landscape. Social Science \& Medicine, 142: 56-67. 